Article

\title{
Control Effects of Five Common Solid Waste Backfilling Materials on In Situ Strata of Gob
}

\author{
Peng Huang ${ }^{1,4} \oplus$, Sam Spearing ${ }^{2, *}$, Feng Ju ${ }^{3, *}$, Kashi Vishwanath Jessu ${ }^{2}$, Zhongwei Wang ${ }^{1}$ and \\ Pai Ning ${ }^{3}$ \\ 1 School of Mines, China University of Mining and Technology, Xuzhou 221116, China; \\ cumt_hp@126.com (P.H.); wzw19910518@163.com (Z.W.) \\ 2 Western Australia School of Mines, Curtin University, Kalgoorlie, WA 6430, Australia; kashijessu@gmail.com \\ 3 State Key Laboratory for Geomechanics and Deep Underground Engineering, China University of Mining \\ and Technology, Xuzhou 221116, China; 17851146436@163.com \\ 4 State Key Laboratory of Coal Resources and Safe Mining, China University of Mining \& Technology, \\ Xuzhou 221116, China \\ * Correspondence: sam.spearing@curtin.edu.au (S.S.); juf1983@163.com (F.J.)
}

Received: 18 September 2018; Accepted: 10 October 2018; Published: 2 January 2019

\begin{abstract}
Solid backfill mining as a green mining method has already been successfully applied in many mine sites. Higher requirements for the backfilling materials have been put forward in special regions, such as shallow coal seams, ecologically susceptible areas, and sites with building on the surface. The control effects of common backfilling materials on in situ strata of gob need to be studied and compared to ensure the suitable materials are applied in the mine. The meso-structure, stress variation, energy dissipation, and backfilling effects of the five common solid backfilling materials, which are Aeolian sand, gangue, mineral waste residue, coal ash, and loess are analyzed in this paper. The results show that the Aeolian sand and gangue are densely packed and internally hard when compared to other backfill materials. The deformation of the five materials to absorb the same amount of energy in the order of higher to lower was determined as Aeolian sand, gangue, mineral waste residue, coal ash and loess. The Aeolian sand's strain energy density is 1.67 times larger than the loess, however, the Aeolian's strain energy density in front of working face is just $32.2 \%$ of the loess, which is important to ensure the safety of the working face. The stress changes were monitored in situ with Aeolian sand and gangue as backfill materials. The monitoring results show that the Aeolian sand stress increase rate is quicker than gangue, which can support the roof effectively.
\end{abstract}

Keywords: green mining; solid backfilling material; energy dissipation; compaction property; meso-structure

\section{Introduction}

Solid Backfill Mining (SBM) as a green mining method has already been applied successfully in many coal mines in China. Backfilling materials, such as gangue, coal ash, loess, etc., were delivered to fill the empty area in SBM [1-3]. In one SBM mine site or digging, however, different backfilling material perform different compressive properties. The backfilling material selection not only considers the convenience of obtaining and the cost but also pays attention to its backfilling effect, especially in shallow depth or thin bedrock or high mine height coal mine site. For example, Aeolian sand and loess cost less and are easy to obtain if used as backfilling material in the west of China, due to lots of those material covering the surface. In that region, meanwhile, the thick and shallow coal seam, thin bedrock, and fragile ecological environment all need the high resistance requirement of backfilling material [4-7]. 
The key to applying SBM successfully is its compaction property, which affects the rock layer deformation, fracture, and energy release $[8,9]$. During compaction, the backfill material's porosity, deformation, stress variation, and energy absorption are important factors affecting the backfill effect [10]. In the last decades, many theoretical studies evolved on the gangue deformation during the compaction test. Wu [11] studied solid backfilling materials compaction characteristics from stress and strain relationship. Huang et al. [12] researched the strata movement control with backfilling the gangue and coal ash mixture into gob. Liu [13] studied the gangue compaction mechanical property in SBM. Actually, the horizontal distortion is almost unconfined in a mine site $[14,15]$. The deformation being considered solely as an influence factor is insufficient. Therefore, the material stress and strain energy during compaction are put forward as another index to indicate the backfilling effect. Little research has been conducted on energy release of backfilling materials. Zhou et al. [16] tested energy dissipation of gangue in the loading process under conditions of different particle sizes, loading rates, and first-time stress loads. Less research focuses on or compares with the five common solid backfilling materials' stress.

Thus, this paper compares five different types of solid backfill in regard to meso-structure by using scanning electron microscopy, compaction properties, stress distribution, and energy dissipation. Results from monitoring of stress variation with two different backfill materials from the mine site are discussed.

\section{Basic Principles of SBM and Influence Factor}

\subsection{Basic Principles of SBM}

In SBM, solid waste materials, such as Aeolian sand, gangue, coal ash, mineral waste residue, and loess, are transported through a vertical pipe and then delivered to the backfilling area with the belt conveyor and the self-moving loading mechanism. The unload hole is well-organized to unload the backfilling materials to the empty area and then using the punning structure to make the backfilling materials denser. When compared with the conventional face layout, a belt conveyor in the tailgate in an SBM face delivers the filling materials to a conveyor in the gob side face behind the shield supports [17]. Therefore, in SBM, the face layout allows simultaneous mining and backfilling operations.

\subsection{Key Influence Factor in SBM}

With the advancing working face, the roof begins to sink and the backfilling materials are compacted progressively. The backfilling material plays a very important role that supports the roof in the gob, which requires the backfilling material to undergo small deformation during compaction and absorb more energy from the roof [18]. The ideal result with the backfill that needs to be achieved is to form a fissure and bending zones in the overburden rock layers to the limit where the formation of a caving zone is initiated [19], as shown in Figure 1. Therefore, different materials have a different effect on the cracks and deformation of the overburden rock layer in the gob. 


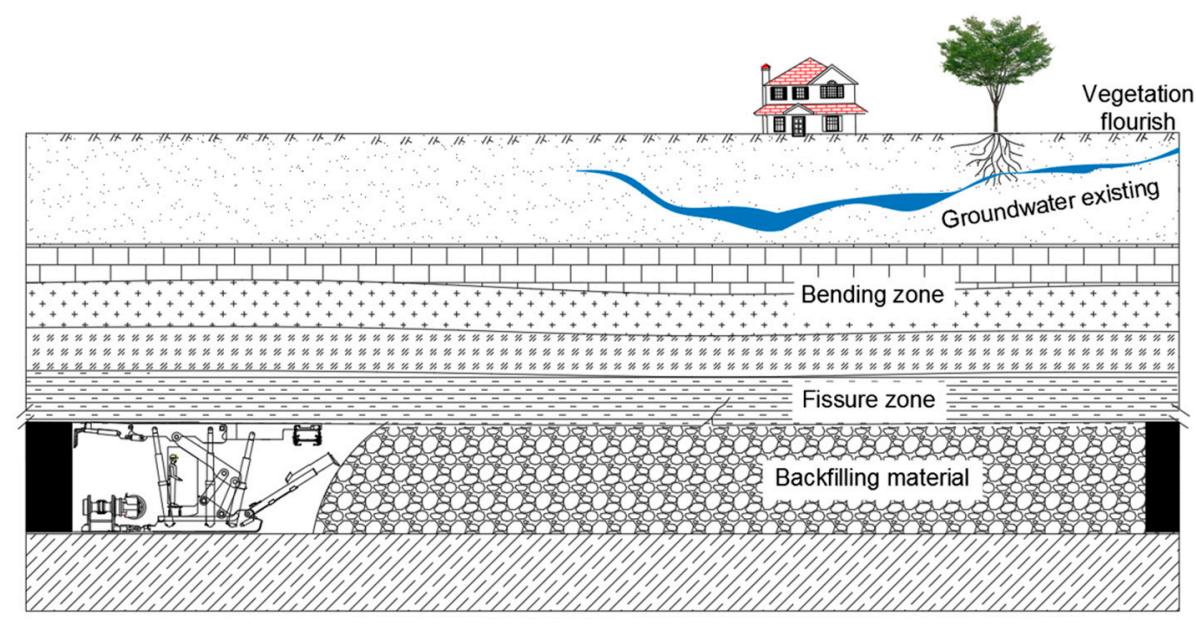

Figure 1. The movement of overburden rock layer in Solid Backfill Mining (SBM).

The five common solid backfilling materials, which are Aeolian sand, gangue, mineral waste residue, coal ash, and loess, are distributed in different ways. In Eastern China, lots of gangue is produced from mine sites; in the north of Chian, the loess and Aeolian sand are covered in the surface, which means the materials are cheap; in the western area of China, lots of mineral waste residue are produced from the open pit. Considering the cost of backfilling materials and the convenience of obtaining them, the common backfilling materials compaction property needs to be studied.

\section{Backfilling Material Meso-Structure}

\subsection{Source of Backfill Materials}

The Aeolian sand was selected from the Yuheng diggings, Shaanxi province. The washing gangue size was filtered under $30 \mathrm{~mm}$ from Dongpin coal mine, Shanxi province. The coal ash was selected from Yangzhuang coal mine power plant, Huaibei city, and then mixed with the water to make its moisture content reach $21 \%$. The loess and mineral waste residue are also from Dong Ping coal mine. The mineral waste residue size was sieved under $50 \mathrm{~mm}$.

\subsection{Scanning Electron Microscope Test}

Five backfilling materials' mesostructure were analyzed by using an FEI Quanta TM 250 scanning electron microscope, as shown in Figure 2. 


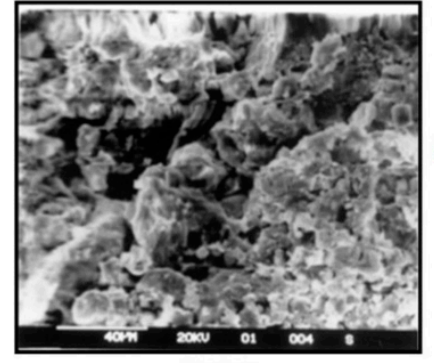

$350 \mathrm{X}$

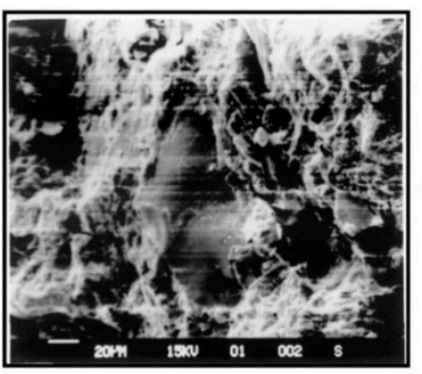

$350 \mathrm{X}$

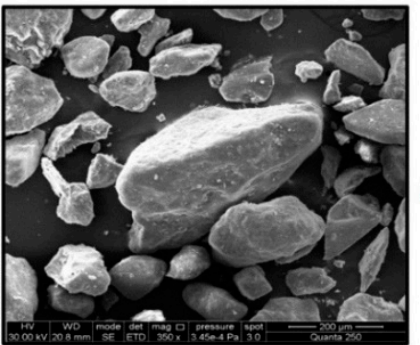

$350 \mathrm{X}$
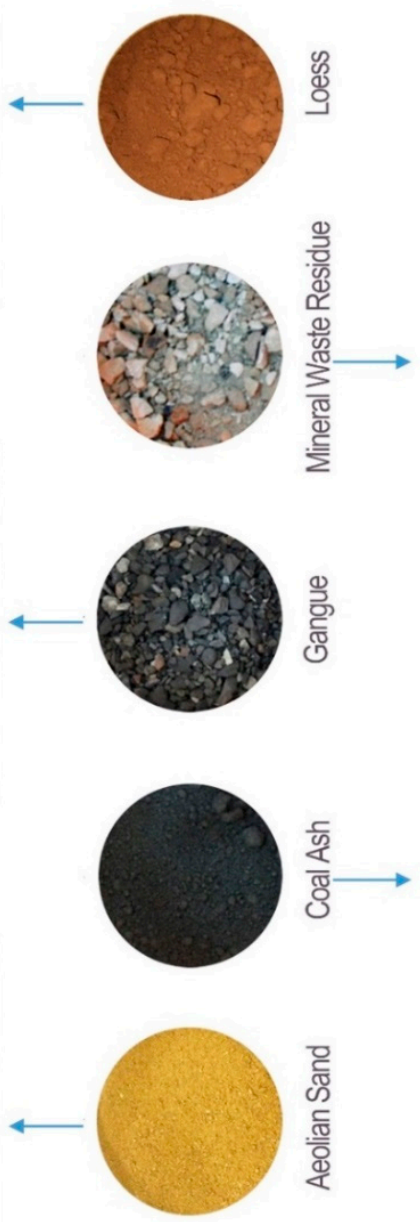

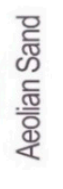

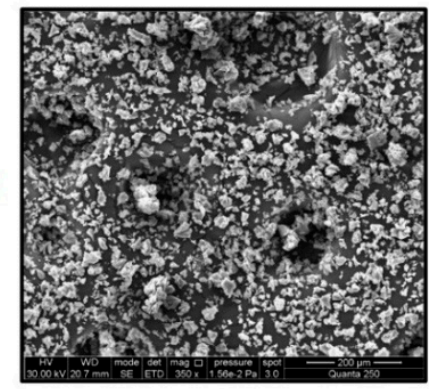

$350 \mathrm{X}$

Figure 2. SEM micrographs of five materials.

As shown in Figure 2, Aeolian sand particles are very small, uniform, dense, and hard, which means efficient pressure transfer among particles. Coal ash is fluffy internally and the particles have an irregularly flaky structure. The gangue particles are dense, small particles filled with few large particles. The mineral waste residue has a large portation of bulky mineral. The loess has developed intergranular mesopores and micropores, with good connectivity between them, and loose structure.

\section{Backfilling Material Compaction Property and Energy Dissipation Test}

\subsection{Test Equipment and Scheme}

The YAS-5000 electro-hydraulic servo-controlled rock mechanic test system, manufactured by Changchun Kexin Test Instrument Company, was employed for the backfill material compaction tests. The literature [20] gives detailed information about steel circular cylinder for testing. The uniaxial compaction tests were performed on five selected backfilling materials by using the steel circular cylinder, for 0-10 MPa stress in the axial direction, with a loading rate of $1 \mathrm{kN} / \mathrm{s}$.

\subsection{Test Result}

The stress-strain relationships of the five backfilling materials under compaction test were derived, as shown in Figure 3. 


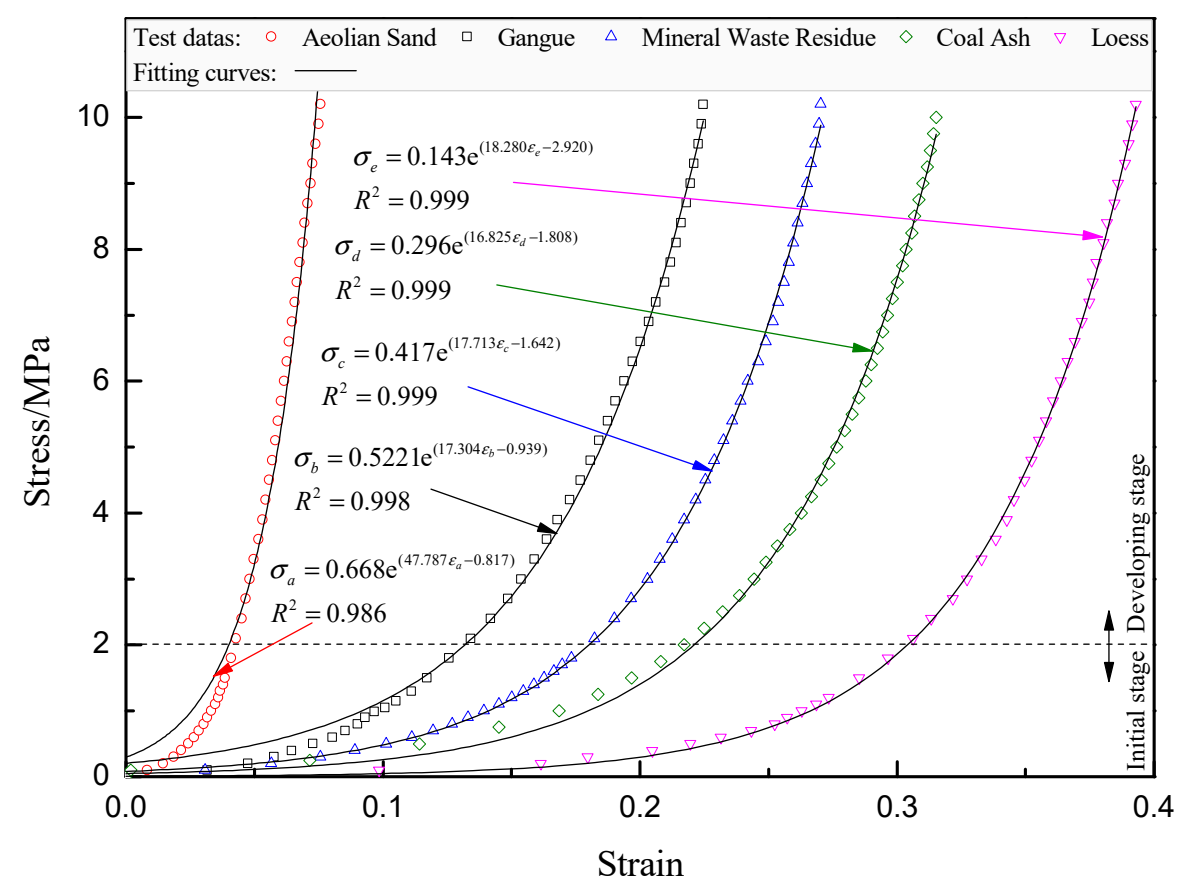

Figure 3. Stress-strain relationship of the five backfilling materials.

As shown in Figure 3, the stress-strain curves of five backfilling materials show an exponential distribution trend. In the initial stage (0-2 MPa), the strain increase is larger and the deformation rate is faster, which accounts for $70-80 \%$ of the total strain. With the gradual increase of pressure, the filling material is gradually compacted and the strain increment decreases gradually. The compaction stress state of the five materials from high to low is Aeolian sand, gangue, mineral waste residue, coal ash, and loess.

The strain energy density of unit volume of material in the process of compaction is given as [16]:

$$
v_{\varepsilon}=\left(1-\frac{\mu \lambda h}{r}\right) \int_{0}^{\varepsilon_{1}} \sigma d \varepsilon
$$

where $\mu$ is the lateral pressure coefficient, $\lambda$ is the friction coefficient of the filling material and the compact cylinder, $\sigma$ is the compaction stress (MPa), $r$ is the steel circular cylinder's inner diameter $(\mathrm{mm})$, and $h$ is the filling height (m).

The strain energy density-strain curve for the five backfilling materials have been calculated and shown in Figure 4. 


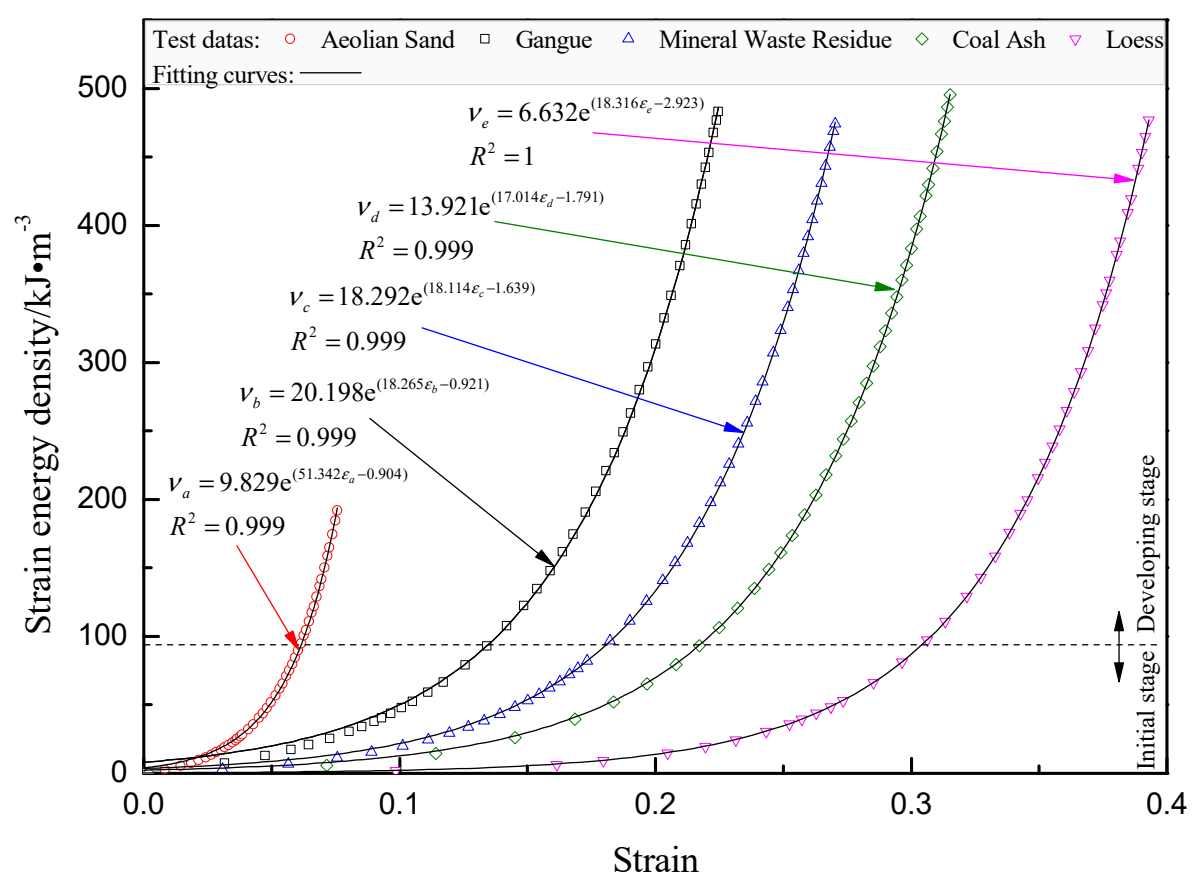

Figure 4. Strain energy density-strain relationship of the five backfilling materials.

As shown in Figure 4, the strain energy density-strain curve of the five materials are also exponentially distributed. In the initial stage ( $0-2 \mathrm{MPa})$, the strain energy density accounts for only $10 \%$ to $30 \%$ of the entire strain energy density. At a constant strain energy density, each material's deformation is different. For example, at a strain energy density value of $100 \mathrm{~kJ} / \mathrm{m}^{3}$, the Aeolian sand strain is 0.063 , meanwhile, the loess's strain is 0.221 . Therefore, to absorb the same amount of energy, the leoss deformation is larger.

Solid backfilling materials are not elastic materials. There is no accurate parameter to express the elastic modulus. The modulus in the compression process is defined as the slope of the trend line within a range of the stress-strain curve. The expression is given as:

$$
E_{s}=\frac{\sigma_{i}-\sigma_{0}}{\varepsilon_{i}-\varepsilon_{0}}
$$

where $\sigma_{i}(\mathrm{MPa})$ and $\varepsilon_{i}$ are the arbitrary point stress and strain, respectively, and $\sigma_{0}(\mathrm{MPa})$ and $\varepsilon_{0}$ are the zero point stress and strain, respectively. The relationship of the five backfilling materials' modulus and stress is shown in Figure 5. 


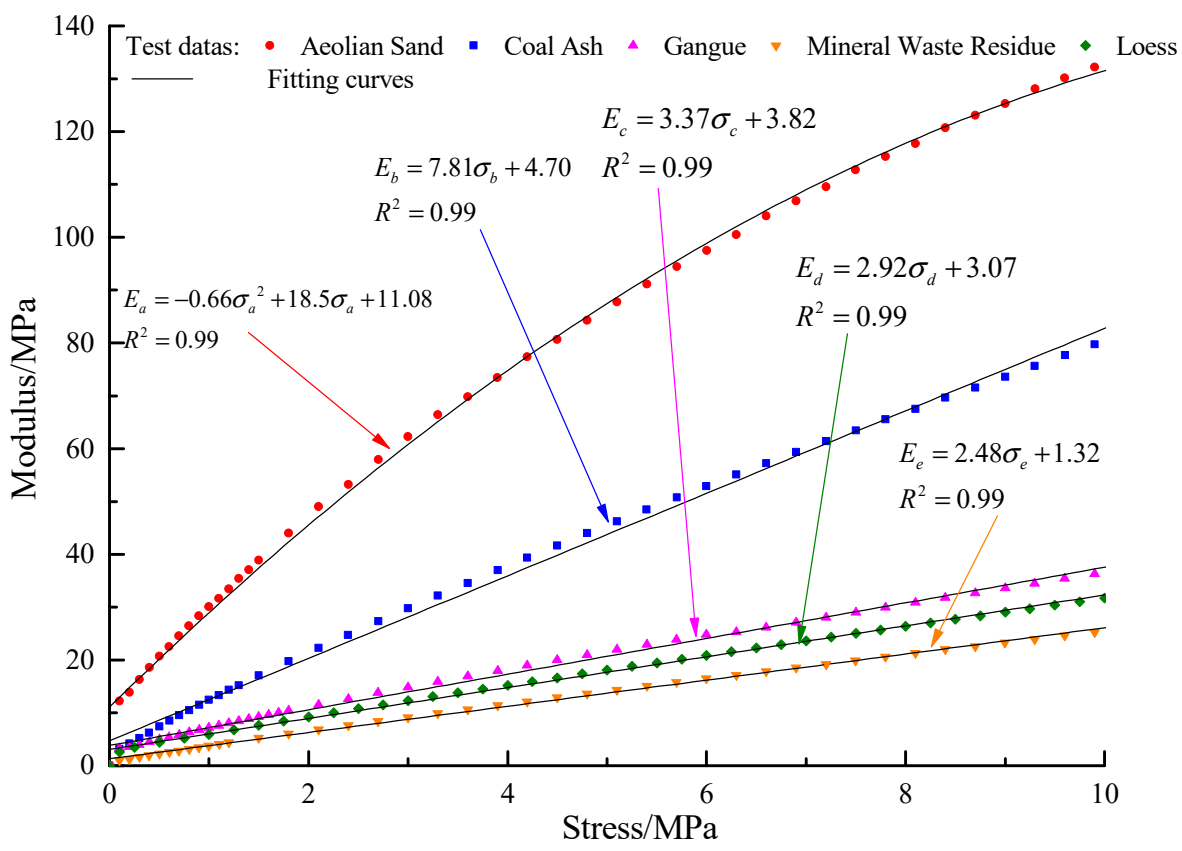

Figure 5. Relationship cave of five materials modulus and stress.

As shown in Figure 5, the modulus and stress curve of the five materials is a linearly distributed trend. However, the modulus change rate is different. Under the same stress, the Aeolian sand has the highest modulus, which means this material has a high non-deformability. The fitting function can be used to simulate the filling body deformation.

\section{Filling Effect of Five Solid Backfilling Materials Using Simulation Method}

\subsection{Engineering Background}

Dong Ping Coal Mine is located west of Mt. Taihang with a typical rolling terrain. The first backfill panel was 15,061, the average length along the strike direction was $286 \mathrm{~m}$ and the average width along the dip direction was $84 \mathrm{~m}$. The panel is mined in the \#15 coal seam, a lower segment of the Taiyuan group which has an average height of $6.8 \mathrm{~m}$. The average depth of the coal seam is $160 \mathrm{~m}$. The mining was conducted in the lower part of the coal seam with $3.0 \mathrm{~m}$ height and the remaining $3.8 \mathrm{~m}$ served as the immediate roof. The backfill material was selected as gangue. The bore hole columnar section and the rock stratum's basic mechanic properties tested in laboratory are shown in Figure 6. 


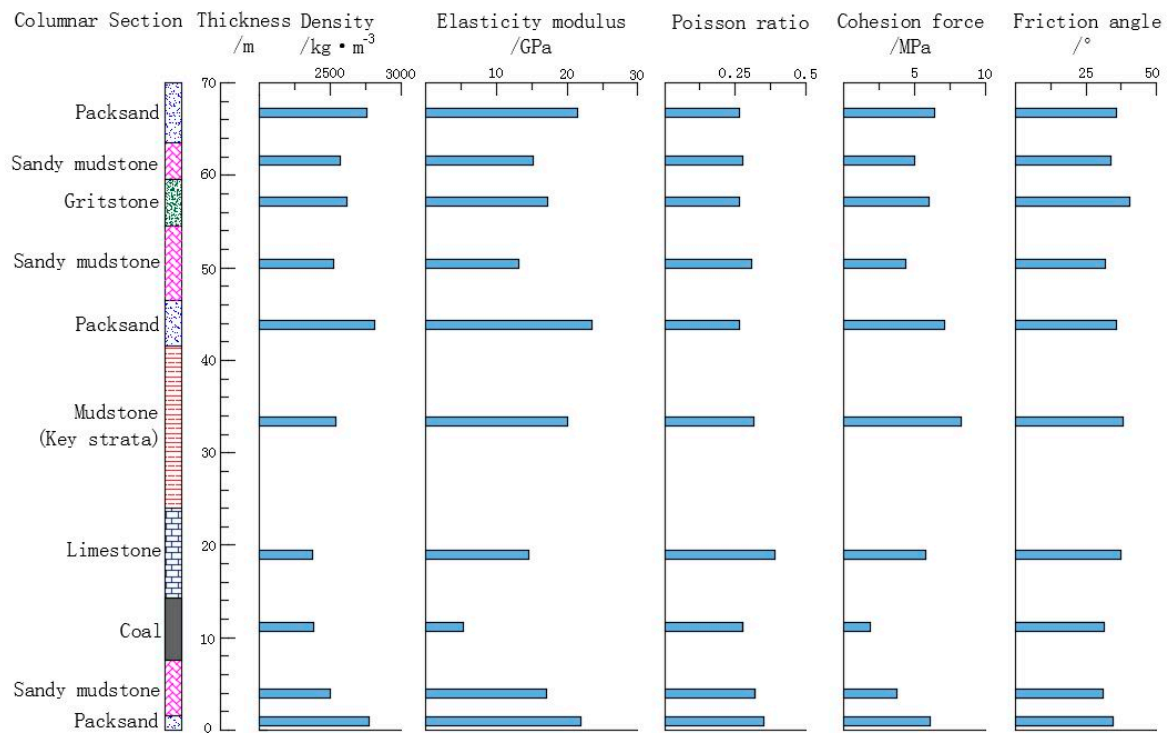

Figure 6. Rock stratum columnar condition and basic mechanical properties.

\subsection{Simulation Model}

FLAC3D numerical simulation software was used to investigate the filling effect of five different backfilling materials. A numerical model was built based on the size of panel 15,061, with a total width in y-direction of $188 \mathrm{~m}$, the length of one zone is $2.5 \mathrm{~m}$ total length in $\mathrm{x}$-direction of $380 \mathrm{~m}$, the length of one zone is $4 \mathrm{~m}$, height in z-direction of $70 \mathrm{~m}$, the length of one zone is $4 \mathrm{~m}$, and a barrier pillar width of $50 \mathrm{~m}$, as shown in Figure 7. The geostress in mine site is main affected by the vertical stress by monitoring the crustal stress. Thus, the uniform vertical stress, $2.5 \mathrm{MPa}$, was applied at the top of the model. The Mohr-Coulomb model was adopted for the rock strata and strain soften model used in the coal seam. After mining the coal seam, filling with the backfilling materials which compaction property, such as dynamic deformation modulus, operated by writing the fish language into the backfilling model.

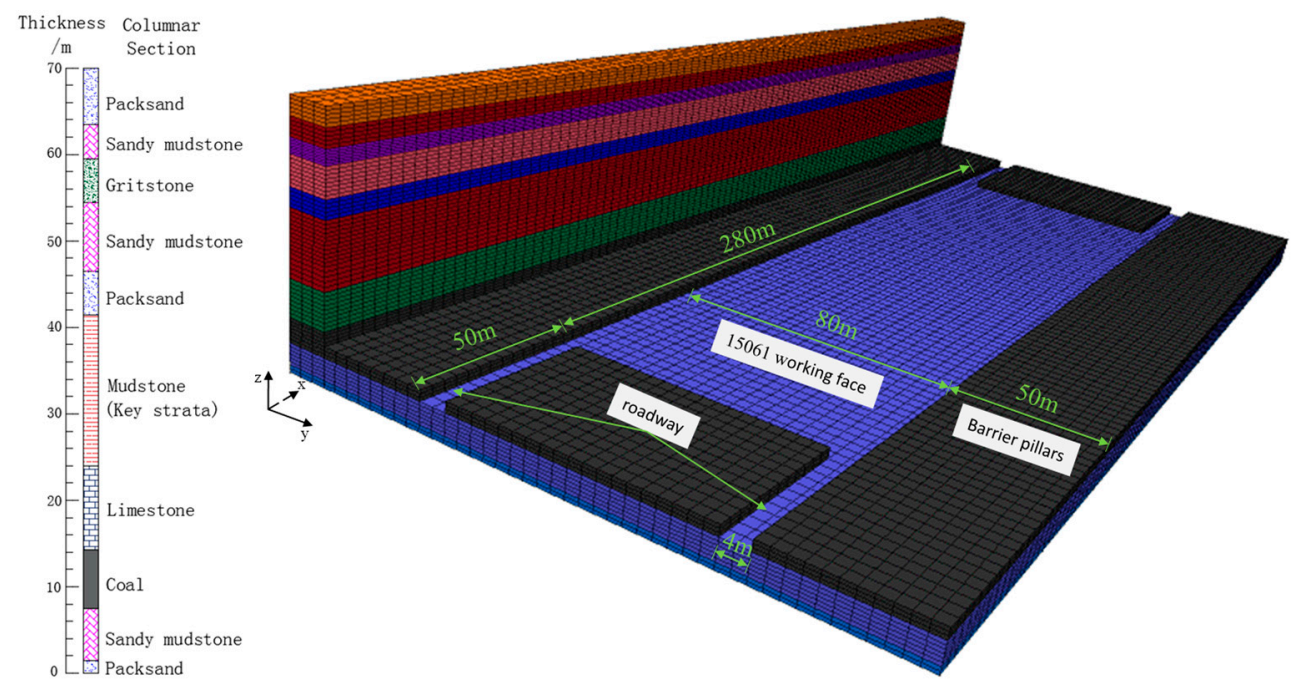

Figure 7. Simulation model. 
Due to the large number of irregular joints and cracks in the rock mass, a series of rock strengths and equations was created to calibration model [21-23]. The strength of the in situ rocks was determined from the laboratory scale strength using the relationship suggested by Bai [24]:

$$
\sigma_{r}=\left(\frac{E_{r}}{E_{l}}\right)^{q} \sigma_{l}
$$

where $\sigma_{l}(\mathrm{MPa})$ and $E_{r}(\mathrm{GPa})$ are the compressive strength and elastic modulus of the laboratory intact rock, respectively; $\sigma_{r}(\mathrm{MPa})$ and $E_{l}(\mathrm{GPa})$ are the compressive strength and elastic modulus of the rock mass, respectively; $\mathrm{q}$ is an empirical parameter taking the value of 0.7 in this paper.

Similarly, the elastic modulus of the in situ rocks was determined from the laboratory scale elastic modulus using the relationship suggested by Bai [24]:

$$
E_{r}=10^{0.0186 R Q D-1.19} E_{l}
$$

where the RQD was evaluated by the integrity of rock mass by the borehole peep.

The laboratory scale uniaxial compressive strength and the elastic modulus are shown in Table 1, which were reduced by Equations (3) and (4) to simulate the models. The density, friction angle, cohesion, and Poisson's ratio of rock were not altered. The tensile strength was set to $10 \%$ of the large-scale rock compressive strength.

\begin{tabular}{|c|c|c|c|c|c|c|}
\hline \multirow{2}{*}{ Lithology } & \multicolumn{2}{|c|}{ Intact Rock } & \multirow{2}{*}{ RQD } & \multicolumn{3}{|c|}{ Rock Mass } \\
\hline & $E_{I} / \mathrm{GPa}$ & $\sigma_{\mathrm{c}} / \mathrm{MPa}$ & & $E_{R} / \mathrm{GPa}$ & $\sigma_{\mathrm{cR}} / \mathrm{MPa}$ & $\sigma_{\mathrm{tR}} / \mathrm{MPa}$ \\
\hline Packsand & 32.3 & 47.6 & 89 & 18.0 & 31.6 & 3.2 \\
\hline Sandy mudstone & 15.8 & 35.5 & 91 & 9.6 & 25.0 & 2.5 \\
\hline Gritstone & 27.1 & 50.7 & 93 & 17.9 & 37.9 & 3.8 \\
\hline Sandy mudstone & 14.5 & 33.6 & 90 & 8.4 & 23.0 & 2.3 \\
\hline Packsand & 34.8 & 47.4 & 95 & 25.0 & 37.6 & 3.8 \\
\hline Mudstone & 20.3 & 35.2 & 89 & 11.3 & 23.4 & 2.3 \\
\hline Limestone & 15.2 & 21.5 & 83 & 6.5 & 11.9 & 1.2 \\
\hline Coal & 7.4 & 9.6 & 62 & 1.3 & 2.8 & 0.3 \\
\hline Sandy mudstone & 18.2 & 36.8 & 81 & 7.2 & 19.2 & 1.9 \\
\hline Packsand & 34.1 & 45.6 & 89 & 19.0 & 30.3 & 3.0 \\
\hline
\end{tabular}

Table 1. The mechanical parameters of rock and coal.

In Flac ${ }^{3 \mathrm{D}}$ software, the modulus of the material is defined by the bulk modulus and shear modulus. The equation of the bulk modulus and shear modulus used by the elastic modulus is as follows:

$$
\left\{\begin{array}{c}
G=\frac{E_{r}}{2(1+\mu)} \\
K=\frac{E_{r}}{3(1-2 \mu)}
\end{array}\right.
$$

where the $G$ is the shear modulus, GPa; $K$ is the bulk modulus, GPa; $\mu$ is Poisson's ratio.

The constitutive behaviour of the five backfilling materials can use the fitting formula in the Figure 3. Similarly, the relationship of elastic modulus and the stress can be adopted from the equations in Figure 5. For example, which relationship of elastic modulus and the stress for gangue is:

$$
E_{r}=3.984 \sigma_{b}+6.142
$$

where the $\sigma_{b}$ is the stress applied to the backfilling materials, MPa.

The bulk modulus and shear modulus of the gangue can be written as:

$$
\left\{\begin{array}{l}
G=\frac{3.984 \sigma_{b}+6.142_{r}}{2(1+\mu)} \\
K=\frac{3.984 \sigma_{b}+6.142}{3(1-2 \mu)}
\end{array}\right.
$$


By using the FISH language code embedded in the FLAC3D software, the stress in gangue can be monitored to recalculate the bulk modulus and shear modulus of the gangue by using the equation (7). Then reassign the bulk modulus and shear modulus in every 20 steps to simulate the gangue deformation property. Similarly, for other backfilling materials, deformation characteristics were simulated with their respective equations from Figure 5.

\subsection{Stress Distribution of Five Backfilling Materials}

The backfilling material's modulus and stress follow the path shown in Figure 5. The backfilling material's vertical stresses were obtained as shown in Figure 8.
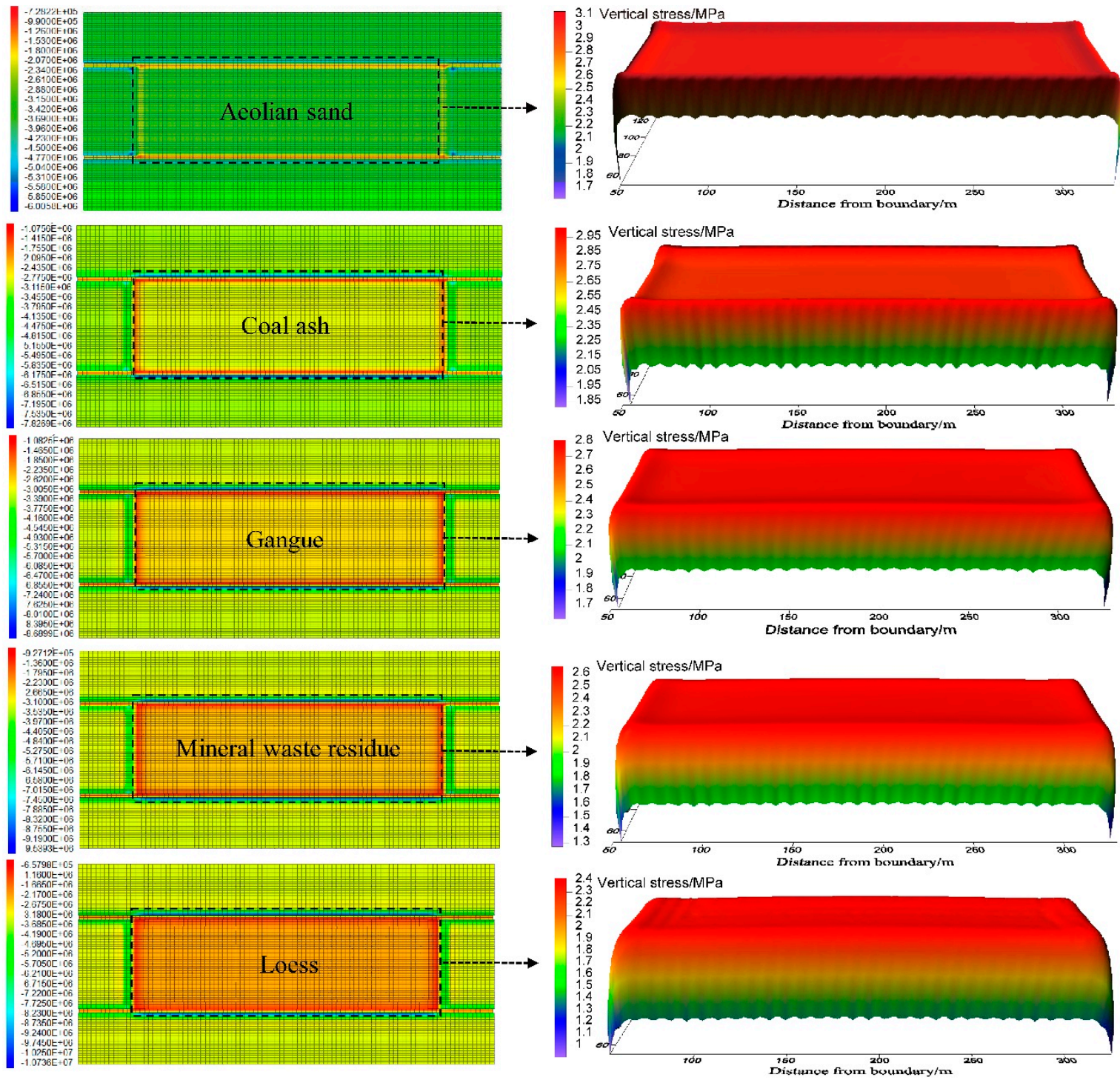

Figure 8. Five backfilling materials compaction stress in SBM.

The pressure from the overlying roof will be applied to the front of the working face and backfill materials in SBM [25]. As shown in Figure 8, in SBM, the backfilling material's stress is higher while the abutment pressure is reduced. This indicates that the backfilling materials can share part of the pressure with the boundary coal pillar. The higher compaction stress of the backfilling materials also signifies the better resistance, such as Aeolian sand and coal ash. Meanwhile, the abutment pressure in front of working face is lower with Aeolian sand and coal ash than other backfilling materials, which 
is important to ensure the safety of the working face, because the Aeolian sand and coal ash backfilling material bear more pressure from the overlying strata when compared to other materials.

\subsection{Strain Energy Density Distribution of Five Backfilling Materials}

According to elastic mechanics, the strain energy density can be expressed as follows [26]:

$$
v_{\varepsilon}=\frac{1}{2 E}\left[\sigma_{1}^{2}+\sigma_{2}^{2}+\sigma_{3}^{2}-2 \mu\left(\sigma_{1} \sigma_{2}+\sigma_{1} \sigma_{3}+\sigma_{2} \sigma_{3}\right)\right] .
$$

Using the FISH language and Equation (5) to configure a new variate: strain energy density, the five backfilling materials' strain energy density are shown in Figure 9.

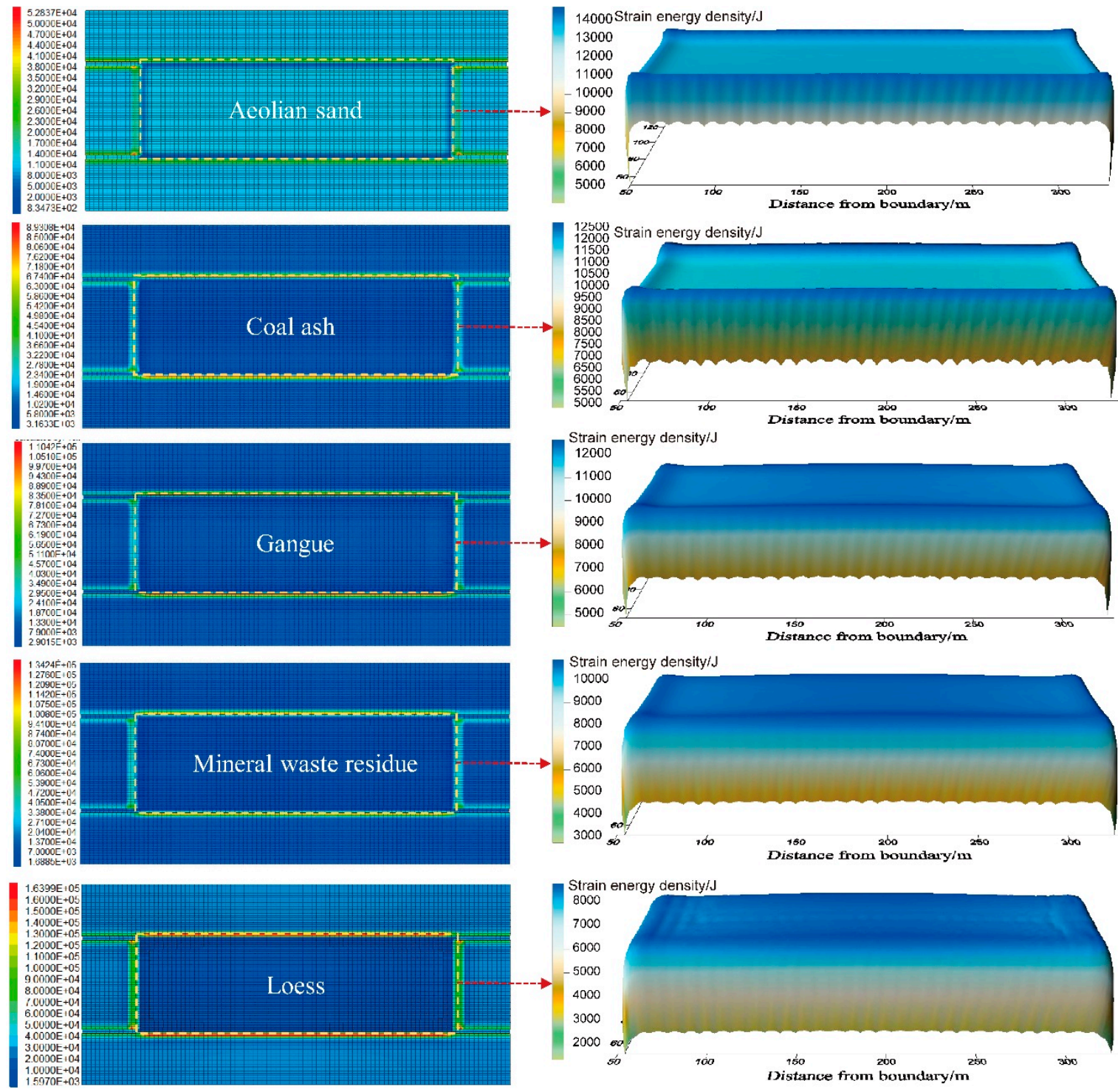

Figure 9. Five backfilling materials compaction strain energy density in SBM.

As shown in Figure 9, backfilling materials can absorb the energy that is induced from the overlying roof deformation and cracks. The more energy the filling materials absorb, the less energy release in working face, which is a benefit to the safety of a mine. For example, Aeolian sand backfilling material has a higher compaction resistance compared to other materials, therefore, large energy in 
stope is absorbed by the Aeolian. The Aeolian sand strain energy density is 1.67 times larger than the loess, however, the Aeolian strain energy density in front of the working face is just $32.2 \%$ of the loess.

In special regions, such as shallow coal seams, ecologically susceptible areas, rock burst prone and sites with building on the surface, the backfilling materials should select the higher compaction resistance materials, such as Aeolian sand and gangue.

\section{Engineering Application}

\subsection{Monitoring Scheme}

In order to compare the different backfilling materials stress change and filling effect, two mine sites were selected. One of the mine sites is Dongpin coal mine and the other is the Taiyuan coal mine, which is located at Yulin, Shanxi province. The Aeolian sand is used as backfilling material in Taiyuan coal mine and gangue in the Dongpin coal mine. A series of rock stress sensors are installed in the backfilling materials to monitor the stress in the two mine sites, the schematic of which is shown in Figure 10.

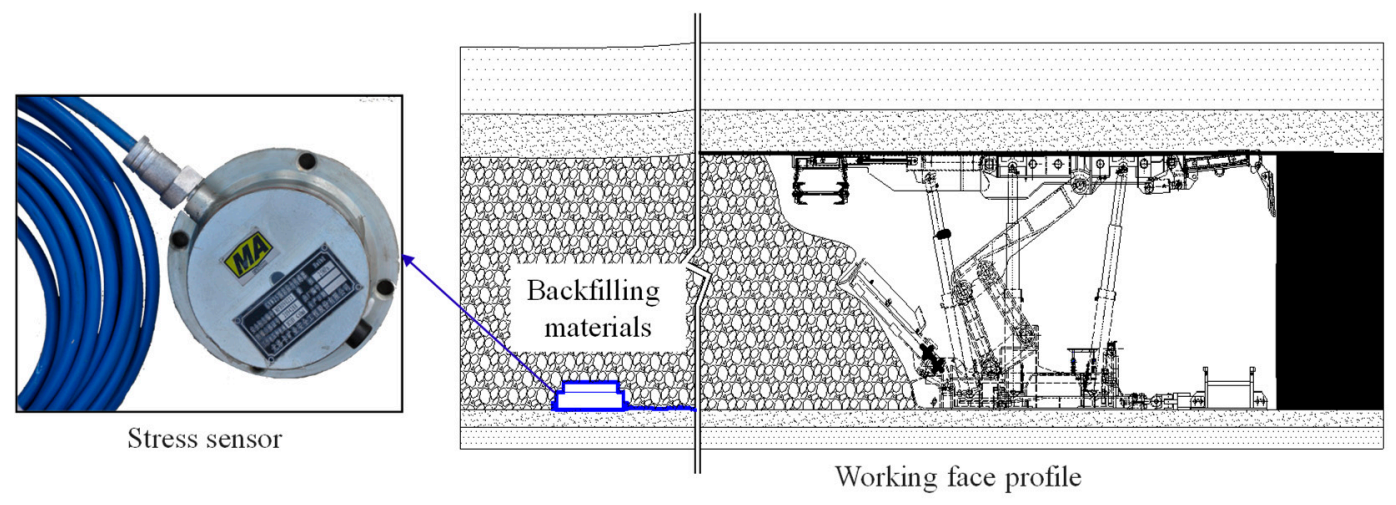

Figure 10. Backfilling material stress monitor scheme.

\subsection{Backfilling Material Stress}

The gangue and Aeolian sand dynamic stress distribution during compaction in each mine site is shown in Figure 11.

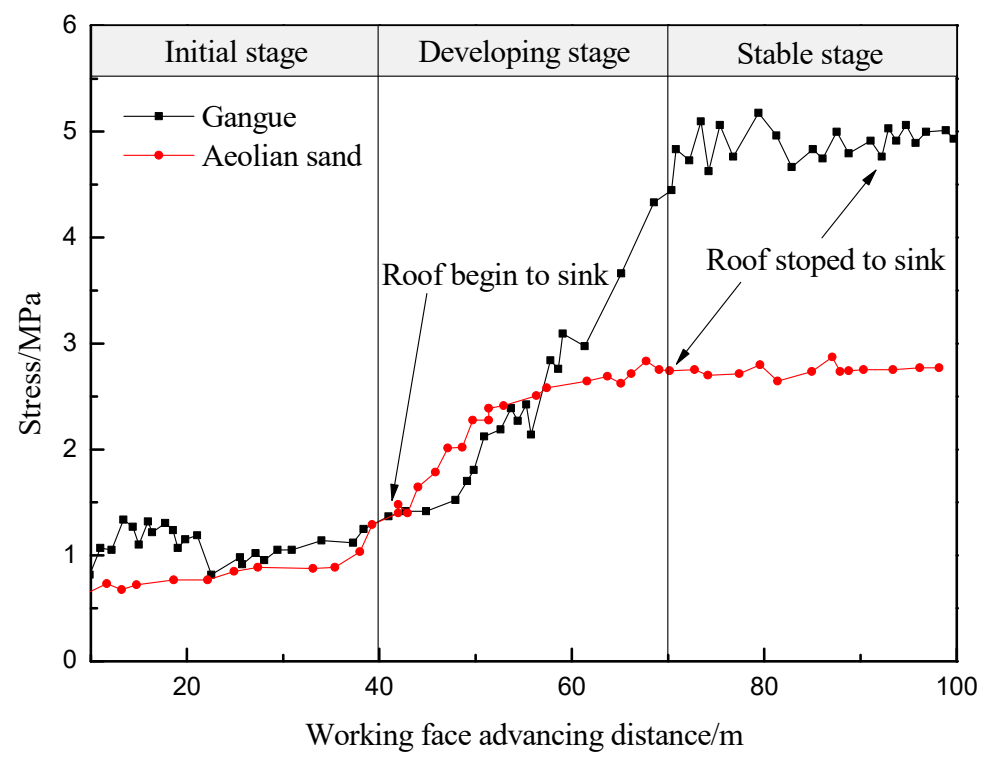

Figure 11. Gangue dynamic stress distribution in SBM. 
The stress in the backfill started to increase after the face advanced by $42 \mathrm{~m}$ (Figure 11) which indicates the roof started to sink in the gob. The stress increase rate at its peak in the Aeolian sand is higher than the gangue indicating that the roof can be stabilized at a quicker rate with Aeolian sand. It also shows that the peak stress where the roof is stabilized is lower for Aeolian sand (i.e., 2.7 MPa) where as for gangue the peak stress is $5 \mathrm{MPa}$. The peak stress in the Aeolian Sand is reached when the advancing face has reached $55 \mathrm{~m}$, while the peak stress for the gangue is not reached until $63 \mathrm{~m}$. This indicates the Aeolian sand is a better backfill material than the gangue.

\section{Conclusions}

1. The basic principles of SBM were introduced and the key factor that influences the strata control is the backfilling material. In some special areas, the requirement of strata control is higher, which does not only need considering of the cost of backfilling material but also needs investigation its compaction property.

2. In microscopic view, five common backfilling materials meso-structure were tested, the Aeolian sand and gangue are dense, hard, and the interior structure is more stable than the other three materials, which means pressure among particles is transferred effectively.

3. In macroscopic view, five common backfilling materials compaction laboratory test shows that in the initial stage (0-2 MPa), the strain increase is larger and the deformation rate is faster, which accounts for $70-80 \%$ of the total strain. At a constant strain energy density, each material's deformation is different. At a strain energy density value of $100 \mathrm{~kJ} / \mathrm{m}^{3}$, the Aeolian sand strain is 0.063; meanwhile, the loess's strain is 0.221 . Under the same stress, the Aeolian sand has the highest deformation modulus which means this material has a high non-deformability.

4. In macroscopic view, the simulation of SBM with five common backfilling materials were built, the result shows that higher compaction stress of the backfilling materials signify better resistance, which is found in Aeolian sand and coal ash. Meanwhile, the abutment pressure in front of working face is lower with Aeolian sand and coal ash than others backfilling materials, which is important to ensure the safety of the working face. The more energy the filling materials absorb, the less energy release onworking face, therefore increasing the safety of a mine. For example, the Aeolian sand strain energy density is 1.67 times larger than the loess, therefore, the Aeolian strain energy density in front of working face is just $32.2 \%$ of the loess, which results in lower abutment pressure.

5. In mine site, gangue and Aeolian Sand dynamic stress distribution during compaction were monitored. In situ measurements determined that the stress increase rate is faster in Aeolian Sand, which can provide support for the roof more effectively and quickly.

Author Contributions: For this paper, P.H. completed experimental tests and wrote the paper; S.S. designed the article structure and proposed many useful recommendations; F.J. put forward study ideas; K.V.J. revised the English writing style; Z.W. collected and analyzed the data from mine site; P.N. conducted the numerical simulation and analyzed the data.

Acknowledgments: This work was supported by the National Natural Science Foundation of China (51674241), and the National Basic Research Program of China (2013CB227905), and the Postgraduate Research \& Practice Innovation Program of Jiangsu Province (KYCX18_1972).

Conflicts of Interest: The authors declare no conflict of interest.

\section{References}

1. Zhang, J.X.; Jiang, H.Q.; Deng, X.J.; Ju, F. Prediction of the Height of the Water-Conducting Zone Above the Mined Panel in Solid Backfill Mining. Mine Water Environ. 2014, 33, 317-326. [CrossRef]

2. Zhang, J.X.; Sun, Q.; Zhou, N.; Jiang, H.Q.; Germain, D.; Abro, S. Research and application of roadway backfill coal mining technology in western coal mining area. Arab. J. Geosci. 2016, 9, 58. [CrossRef] 
3. Miao, X.X. Progress of fully mechanized mining with solid backfilling technology. J. China Coal Soc. 2012, 8, 1247-1255.

4. Xu, Y.N.; Li, Z.P.; Chen, S.B.; Chen, H.Q.; Yuan, H.C. Effect of coal mining collapses of the Daliuta coal mine on land desertification. Geol. China 2008, 1, 157-162.

5. Zhang, F.; Liu, W.S. A numerical simulation on the influence of underground water flow regime caused by coal mining-A case study in daliuta, shenfu mining area. J. Saf. Environ. 2002, 4, 30-33.

6. Wang, H.L.; Li, W.J.; Chen, Y.J. Impact on ground water by coal mining in daliuta, shenmu area. Geol. Shaanxi 2002, 20, 89-96.

7. Lu, C.P.; Dou, L.M.; Wang, Y.F.; Du, T.F. Microseismic effect of coal materials rockburst failure induced by hard roof. Chin. J. Geophys. 2010, 53, 450-456.

8. Zhang, J.X.; Zhou, Y.J.; Huang, Y.L. Integrated Technology of Fully Mechanized Solid Backfill Mining. J. China Coal Soc. 2012, 11, 10-13, 27.

9. Miao, X.X.; Zhang, J.X.; Guo, G.L. Study on waste-filling method and technology in fully- mechanized coal mining. J. China Coal Soc. 2010, 35, 1-6.

10. Miao, X.X.; JU, F.; Huang, Y.L.; Guo, G.L. New development and prospect of backfilling mining theory and technology. J. China Univ. Min. Technol. 2015, 44, 391-399, 429.

11. Wu, X.G. Mechanical Properties of Solid Filling Materials Research and Application; China University of Mining \& Technology: Xuzhou, China, 2014.

12. Huang, P.; Li, B.Y.; Xiao, M.; Chen, Z.W.; Pei, Y.L. The Design of Critical Filling ratio in close distance coal seams by upward backfill mining technology. J. Min. Saf. Eng. 2016, 4, 597-603.

13. Liu, Z. Compaction Properties of Gangue and Its Application in Backfilling Coal Mining; China University of Mining \& Technology: Xuzhou, China, 2014.

14. Wang, L.; Zhang, X.N.; Guo, G.L.; Zha, J.F. Quality control system framework for fully mechanized mining. J. China Coal Soc. 2013, 38, 1568-1575.

15. Wang, L. Study on Strata Movement Mechanism and Deformation Prediction of Coal Mining with Solid Waste Compacted Filling. Ph.D. Thesis, China University of Mining \& Technology, Xuzhou, China, 2014.

16. Zhou, N.; Han, X.L.; Zhang, J.X.; Li, M. Compressive deformation and energy dissipation of crushed coal gangue. Powder Technol. 2016, 297, 220-228. [CrossRef]

17. Deng, X.; Zhang, J.X.; Wit, B.W.; Ju, F. Pressure Propagation Characteristics of Solid Waste Backfilling Material During Compaction and Its Applications In Situ. Geotech. Geol. Eng. 2016, 34, 1631-1642. [CrossRef]

18. Zhang, J.X.; Deng, X.J.; Zhao, X.; Ju, F.; Li, B.Y. Effective control and performance measurement of solid waste backfill in coal mining. Int. J. Min. Reclam. Environ. 2017, 31, 91-104. [CrossRef]

19. Huang, Y.L.; Zhang, J.X.; Zhang, Q.; Nie, S.J.; An, B.F. Strata Movement Control due to Bulk Factor of Backfilling Body in Fully Mechanized Backfilling Mining Face. J. Min. Saf. Eng. 2012, 29, 162-167.

20. Ju, F.; Huang, P.; Guo, S.; Xiao, M.; Lan, L.X. A roof model and its application in solid backfilling mining. Int. J. Min. Sci. Technol. 2017, 1, 139-143. [CrossRef]

21. Mo, S.; Canbulat, I.; Zhang, C.; Oh, J.; Shen, B.; Hagan, P. Numerical investigation into the effect of backfilling on coal pillar strength in highwall mining. Int. J. Min. Sci. Technol. 2018, 28, 281-286. [CrossRef]

22. Wu, S.C.; Zhang, S.; Zhang, G. Three-dimensional strength estimation of intact rocks using a modified Hoek-Brown criterion based on a new deviatoric function. Int. J. Rock Mech. Min. Sci. 2018, 107, 181-190. [CrossRef]

23. Zhang, Y.; Ren, F.Y.; Yang, T.H.; Wang, S.Y.; Zhang, W.F.; Yu, M.X. An Improved Rock Mass Characterization Method Using a Quantified Geological Strength Index and Synthetic Rock Mass Model. Rock Mech. Rock Eng. 2018, 1-16. [CrossRef]

24. Bai, Q.S.; Tu, S.H.; Chen, M.; Zhang, C. Numerical modeling of coal wall spall in a longwall face. Int. J. Rock Mech. Min. Sci. 2016, 88, 242-253. [CrossRef]

25. Zhang, J.X.; Zhou, N.; Huang, Y.L.; Zhang, Q. Impact law of the bulk ratio of backfilling body to overlying strata movement in fully mechanized backfilling mining. J. Mining Sci. 2011, 47, 73-84. [CrossRef]

26. Xu, Z.L. Mechanics of Materals; Higher Education Press: Beijing, China, 2004.

(C) 2019 by the authors. Licensee MDPI, Basel, Switzerland. This article is an open access article distributed under the terms and conditions of the Creative Commons Attribution (CC BY) license (http:/ / creativecommons.org/licenses/by/4.0/). 